\title{
The optogenetic (r)evolution
}

\author{
Martin L. Rein · Jan M. Deussing
}

Received: 25 August 2011 / Accepted: 30 November 2011 / Published online: 20 December 2011

(C) The Author(s) 2011. This article is published with open access at Springerlink.com

\begin{abstract}
Optogenetics is a rapidly evolving field of technology that allows optical control of genetically targeted biological systems at high temporal and spatial resolution. By heterologous expression of light-sensitive microbial membrane proteins, opsins, cell type-specific depolarization or silencing can be optically induced on a millisecond time scale. What started in a petri dish is applicable today to more complex systems, ranging from the dissection of brain circuitries in vitro to behavioral analyses in freely moving animals. Persistent technical improvement has focused on the identification of new opsins, suitable for optogenetic purposes and genetic engineering of existing ones. Optical stimulation can be combined with various readouts defined by the desired resolution of the experimental setup. Although recent developments in optogenetics have largely focused on neuroscience it has lately been extended to other targets, including stem cell research and regenerative medicine. Further development of optogenetic approaches will not only highly increase our insight into health and disease states but might also pave the way for a future use in therapeutic applications.
\end{abstract}

Communicated by J. Graw.

M. L. Rein · J. M. Deussing ( $\square)$

Research Group "Molecular Neurogenetics",

Max Planck Institute of Psychiatry, Kraepelinstr. 2-10, 80804 Munich, Germany

e-mail: deussing@mpipsykl.mpg.de

URL: http://www.mpipsykl.mpg.de/en/research/groups/deussing/ index.html

\section{J. M. Deussing}

Clinical Cooperation Group Molecular Neurogenetics, Institute of Developmental Genetics, Helmholtz Center Munich, Ingolstaedter Landstr. 1, 85764 Neuherberg, Germany
Keywords Optogenetics · Rhodopsin ·

Channelrhodopsin $\cdot$ Halorhodopsin $\cdot$ Optical tools . Arch $\cdot \mathrm{ChR} 2 \cdot \mathrm{NpHR}$

\section{Introduction}

In recent years, optical control of genetically targeted biological systems has been a fast moving field of continuous progress. The combination of optics, genetics and bioengineering to either stimulate or inhibit cellular activity via light-sensitive microbial membrane proteins (opsins) gave birth to a new research discipline named "optogenetics" (Nagel et al. 2002, 2003; Boyden et al. 2005; Deisseroth et al. 2006). Optical control by microbial opsins has several advantages in comparison to classical electrical or multicomponent manipulation techniques. By genetic targeting, optogenetic stimulation and even inhibition of heterogeneous brain tissue can be achieved in a cell type-specific manner. In contrast, electrical stimulation unselectively interferes with all present cell types, regardless of their anatomical or genetic entity (for example excitatory versus inhibitory neurons and local neurons versus projections), thereby diluting the contribution of individual elements on brain circuitries on the overall effect. In opsins, sensor and effector are combined in a monocomponent system and no exogenous genetical or chemical substitution is necessary what makes it more suitable for in vivo experiments in contrast to multicomponent systems, which are limited rather to in vitro applications. As light of moderate intensity does not interfere with neuronal function and opsin latency upon illumination is very short, optogenetics uniquely combines cell type-specific control with millisecond time scale temporal resolution in a fully reversible manner. Once channelrhodopsin 2 (ChR2) and halorhodopsin (NpHR) had been 
recognized as multimodal optical interrogation tools in neuroscience, significant efforts have been made to lift the optogenetic approach to a level of broader applicability (Nagel et al. 2003; Boyden et al. 2005; Deisseroth et al. 2006; Zhang et al. 2007a). Bioengineering of existing opsin genes from different microorganisms generated a variety of chimeric rhodopsin versions with modified properties regarding trafficking, kinetics and light responsivity (Zhao et al. 2008; Airan et al. 2009; Berndt et al. 2008, 2011; Lin et al. 2009; Bamann et al. 2010; Gunaydin et al. 2010; Oh et al. 2010; Han et al. 2011; Kleinlogel et al. 2011; Schultheis et al. 2011; Yizhar et al. 2011a, b). In parallel, opsins from various species were screened for their optogenetic suitability. Channelrhodopsin from different species extended the optical spectrum of cellular excitation and the light-driven proton pumps Arch and ArchT enabled neuronal silencing in addition to halorhodopsin (Zhang et al. 2008; Chow et al. 2010; Govorunova et al. 2011; Han et al. 2011). Starting with proof of principle experiments in frog oocytes, optogenetics has been intensively used in vitro (Nagel et al. 2002; Boyden et al. 2005). With the creation of an optical neural interface, freely moving mammals can be studied in vivo, upgrading the optogenetic toolbox to an instrument for the analysis of such complex biological mechanisms such as animal behavior (for example Aravanis et al. 2007; Adamantidis et al. 2007; Tsai et al. 2009; Carter et al. 2010; Ciocchi et al. 2010; Tye et al. 2011). Beside its role in neuroscience, other research fields recently have started to illuminate ChR2-targeted tissues such as cardiomyocytes and embryonic stem cells, proving the universal capabilities of optogenetics (Bruegmann et al. 2010; Stroh et al. 2011). Continuous progress in optical technologies and opsin engineering will not only further consolidate optogenetics as an excellent experimental tool but will also lay the foundation for potential future therapeutic applications $(\mathrm{Bi}$ et al. 2006; Lagali et al. 2008; Llewellyn et al. 2010; Weick et al. 2010; Kleinlogel et al. 2011) (Table 1).

\section{Exploiting light-sensitive microbial membrane proteins}

With the identification of the gene for a light-responsive membrane protein in microorganisms called bacteriorhodopsin (BR), Stoeckenius and Oesterhelt (1971) set the foundation for a technology, which is today described by the term "optogenetics" (Oesterhelt and Stoeckenius 1973; Deisseroth et al. 2006). Three decades had passed until scientists were able to take advantage of the potential based on the working principle of this seven-transmembrane domaincontaining light-transducing proton pump, which in nature serves microbes, among other things, as a regulator of homeostasis and phototrophy (Beja et al. 2000). Encoded by a single open reading frame, it works as an optical controller of transmembrane ion flow combining fast action and coupling of sensor and effector in a monocomponent system (Oesterhelt and Stoeckenius 1971). Later rhodopsinmediated responses were also studied in the alga Chlamydomonas (Harz and Hegemann 1991) and since the photocurrets were ultra fast the authors claimed that rhodopsin and channel were intimately linked (Holland et al. 1996). Then Nagel and colleagues proved this concept by showing that the Rhodopsins are directly light-gated ion channels. They used amphibian and mammalian cells as hosts to express channelrhodopsin-1 (ChR1), a light-gated proton channel from the green algae Chlamydomonas reinhardtii. In a modified patch clamp set-up they substantiated that rhodopsins react functionally upon laser illumination also in mammalian cells (Nagel et al. 2002). What was initially used as an experimental model system to study channelrhodopsin function turned into the precursor of a novel scientific tool. With the functional characterization of ChR2, a directly light-gated cation-selective membrane channel, Nagel et al. (2003) showed that mammalian cells expressing ChR2 could be depolarized "simply by illumination". The full conversion of this approach into an optical control device of cell activity happened in 2005 when it found its way into neuroscience. The Deisseroth lab applied lentiviral gene delivery to express $\mathrm{ChR} 2$ in rat hippocampal neurons. In combination with high-speed optical switching, neuronal spiking was elicited by photostimulation in a millisecond timescale (Boyden et al. 2005). In parallel, the labs of Yawo, Herlitze and Gottschalk independently demonstrated the feasibility of ChR2-based optical neuronal manipulation ( $\mathrm{Li}$ et al. 2005; Nagel et al. 2005; Ishizuka et al. 2006). The interplay of optics, genetics, and bioengineering in this novel approach was the inspiration to coin the term "optogenetics", which can be defined as optical control of cells achieved by the genetic introduction of light-sensitive proteins (Deisseroth et al. 2006). Another milestone in the evolution of optical control was the discovery of an inhibitory opponent of ChR2. Although relative reduction of neuronal activity had previously been shown for the Gi/o protein-coupled vertebrate rat opsin (Ro4, a type II opsin) by activating $\mathrm{G}$ protein-gated rectifying potassium channels and voltage-gated calcium channels (Li et al. 2005), complete and fast silencing was achieved by using a microbial (type I opsin) chloride pump. Halorhodopsin (HR) had been discovered decades before its conversion into a research tool (Matsuno-Yagi and Mukohata 1977). Expression of Natromonas pharaonis HR (NpHR) in neuronal tissue enables optically induced cellular hyperpolarization by pumping chloride into the cell. Consecutive inhibition of spontaneous neuronal firing can be achieved in a millisecond time scale (Zhang et al. 2007a, b; Han and Boyden 2007). A major advantage compared to Ro4 is the manipulation via $\mathrm{Cl}^{-}$, an ion that is not involved in intracellular 


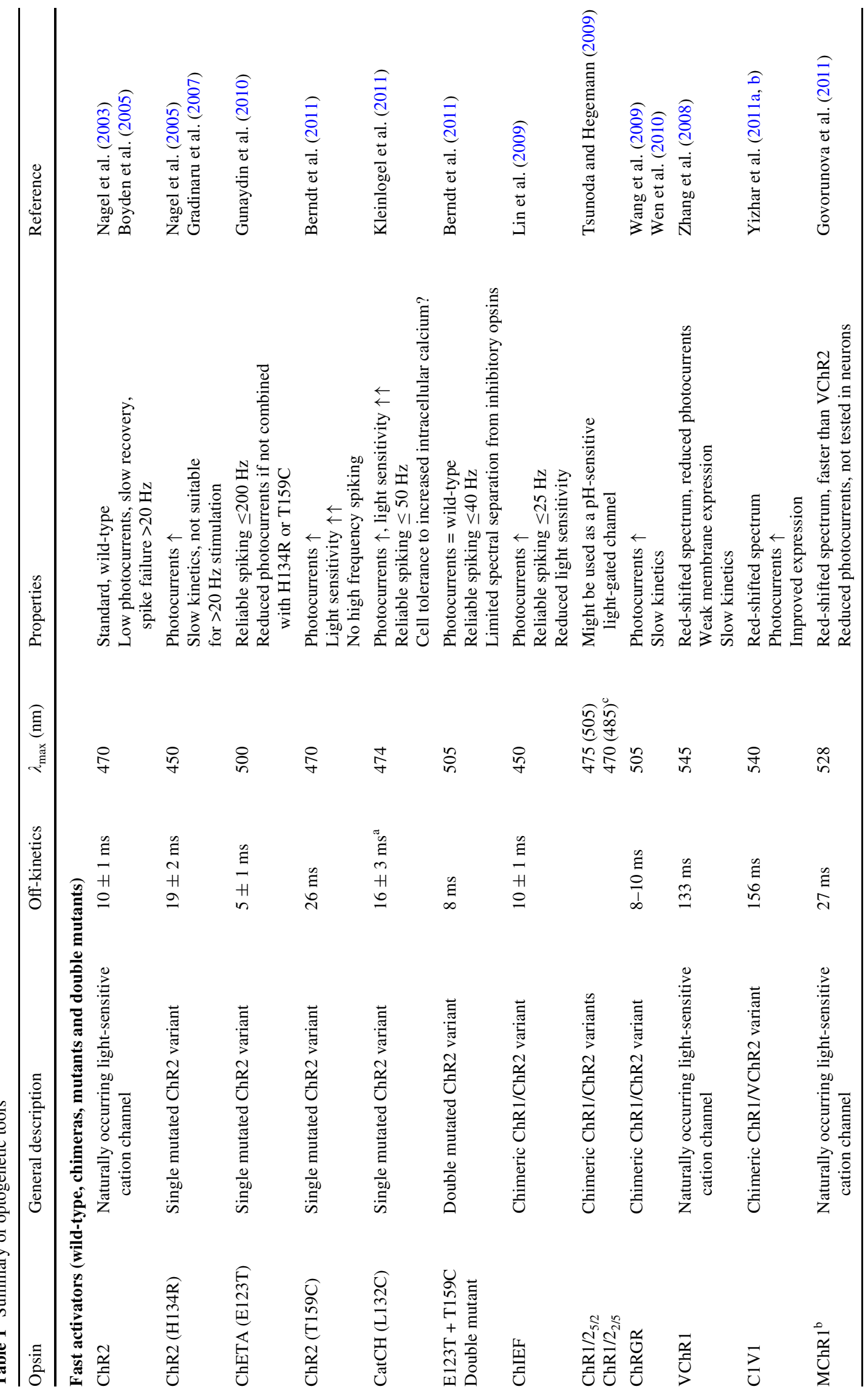




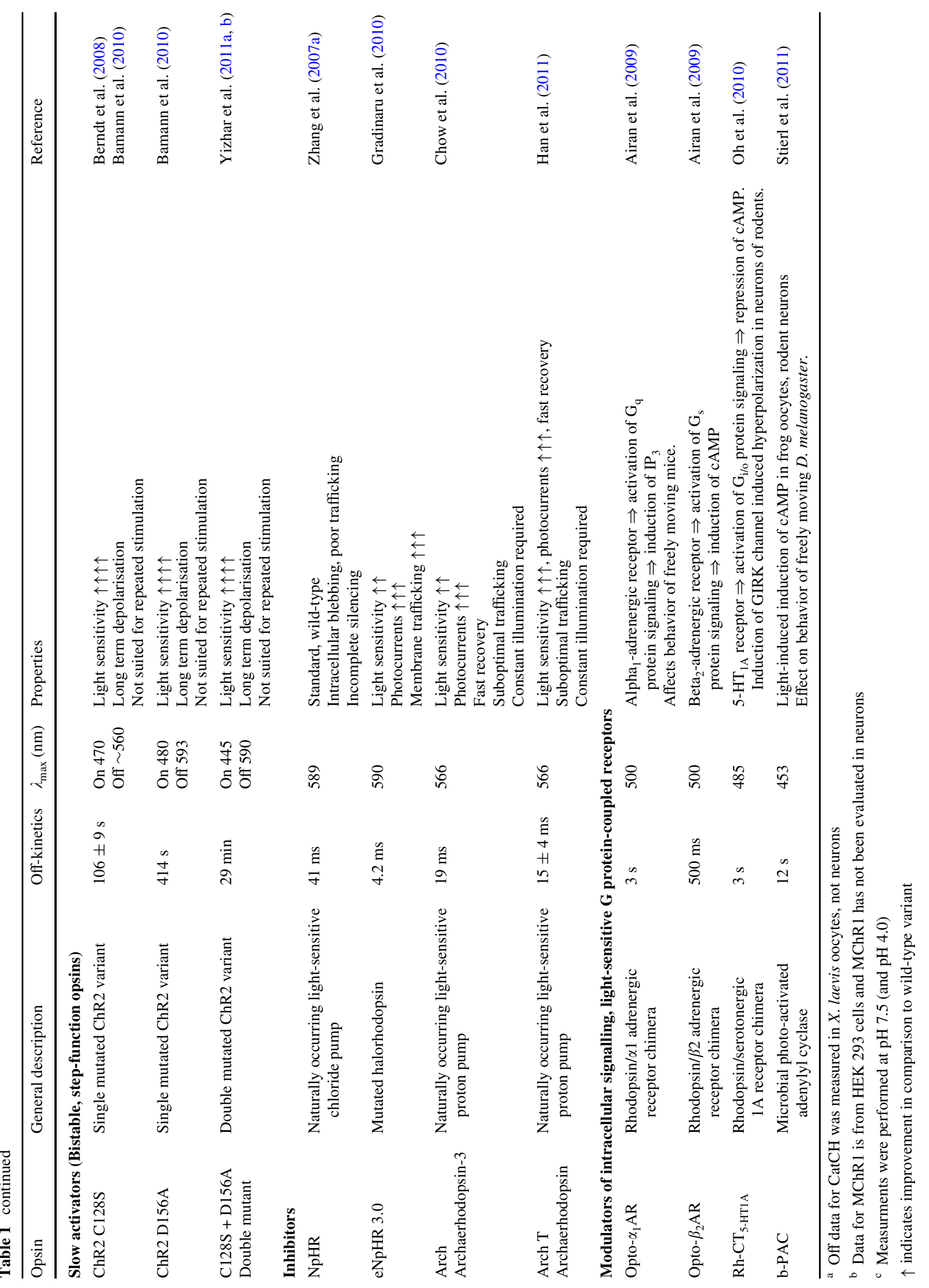


signaling such as calcium and the use of all-trans retinal instead of 11-cis which is functioning as a chromophore in Ro4. Due to spectrally separated activation maxima of $\mathrm{ChR} 2$ and NpHR bidirectional optical modulation is possible, offering excitation and silencing of the same target cell. Even more efficient optical silencers, the proton pumps Arch and ArchT, with similar activation spectra were found in archaebacteria after screening various species (prokaryotes, algae and fungi) for microbial type I opsins (Chow et al. 2010; Han et al. 2011). In an attempt to establish a simultaneous multi-excitatory optical control system by using spectrally separated opsins, red-shifted ChR1 from Volvox carteri (VChR1) was identified. VChR1 works like $\mathrm{ChR} 2$ as a cation channel and extended the optical spectrum of cellular excitation toward green light (Zhang et al. 2008). Yet VChR1 applicability in mammalian cells was strongly limited by small photocurrents due to insufficient membrane expression; a limitation that has been circumvented by the generation of a chimeric channelrhodopsin (C1V1) composed of channelrhodopsin-1 parts from Chlamydomonas reinhardtii and Volvox carteri (Yizhar et al. 2011b). In a very recent publication a new channelrhodopsin from Mesostigma viride (MChR1) with a similarly red-shifted action spectrum has been identified and mutated (Govorunova et al. 2011). Heterologous expression of native MChR1 in HEK293 cells indicated peak currents comparable to VChR1 with faster current kinetics making MChR1 a potential candidate for red-shifted optogenetic control, although toxicity and expression levels in neuronal tissue remain to be analyzed. Channelrhodopsins show structural homology to other type I opsins, however, in their working principle they fundamentally differ from NpHR and BRs like Arch and ArchT (Fig. 1). ChRs are non-selective cation channels that open when illuminated by green light with passive influx of predominantly $\mathrm{Na}^{+}$and, to a lesser extent, $\mathrm{Ca}^{2+}$ ions along a membrane gradient resulting in the depolarization of cells expressing these molecules (Nagel et al. 2003). In contrast, HR and BR are ion pumps that work against an electrochemical gradient across the membrane (Racker and Stoeckenius 1974, Schobert and Lanyi 1982). With an excitation maximum at $589 \mathrm{~nm}$ NpHR pumps chloride into the cell when activated by yellow light causing a hyperpolarization with consecutive silencing of the target cell. Arch and ArchT also hyperpolarize cells, but by pumping $\mathrm{H}^{+}$outwards and in a more rapidly recovering manner. Excitation maxima are at approximately $566 \mathrm{~nm}$ for Arch and ArchT (Chow et al. 2010; Han et al. 2011).

\section{Adjusting microbial opsins to optogenetic needs}

While opsins are designed as the perfect single unit optical regulators of membrane flow in microbes, more complex organisms such as vertebrates in contrast use multicomponent systems of information signaling or energy transduction. After the identification of promising optogenetic candidates, several hurdles had to be smoothed out in order to maximize the compatibility of membrane proteins of microbial origin with their use in mammalian cells. In this regard the transformation of the optogenetic silencing tool NpHR into its updated version eNpHR 3.0, very well exemplifies several aspects of genetic opsin engineering. In order to optimize opsin expression in mammalian cells a codonoptimized variant of NpHR was created in analogy to ChR2 (Boyden et al. 2005; Zhang et al. 2007a). In contrast to the efficient expression of NpHR-EYFP fusion proteins in rat hippocampal neurons in vitro, expression of native NpHR under a strong ubiquitous promoter in mammalian cells in vivo lead to retention in the endoplasmic reticulum causing toxic intracellular accumulation (Zhang et al. 2007a; Zhao et al. 2008). By adding a vertebrate export motif c-terminally, eNpHR 2.0 was generated, resulting in decreased intracellular blebbing and improved membrane trafficking (Gradinaru et al. 2008). After analyzing various transport signals, another c-terminal modification finally brought the breakthrough. eNpHR 3.0 contains an additional trafficking signal leading to improved membrane targeting both at the soma as well as in cellular processes. Consecutive to well tolerated high level in vivo expression of eNpHR 3.0, higher photocurrents can be measured in targeted mammalian neuronal tissue compared to the non-tuned $\mathrm{NpHR}$ (Gradinaru et al. 2010). Up to now bioengineering of optogenetic silencers focused on improving opsin expression and the mentioned principles seem applicable to proton pumps such as Arch as well. Indeed, equipping the original version of BR with an export motive and trafficking signal converted BR from an intracellular accumulator into the optogenetic tool eBR (Gradinaru et al. 2010). In contrast, optimizing the photocycle kinetics in pumps is more difficult since a slow down of the photocycle automatically translates into a lower pump activity.

\section{Creating high-end optogenetic tools}

Engineering of rhodopsins was first introduced by Nagel et al. (2003). Mutating the amino acid 123 from glutamate to glutamine resulted in altered photocurrents of ChR2 when expressed in oocytes from Xenopus laevis. For the use in mammalian neurons codon optimization led to significantly higher expression levels compared to codons used in algae (Boyden et al. 2005; Gradinaru et al. 2007). As high opsin expression is a prerequisite for suprathreshold depolarization, initial modifications focused on boosting photocurrents. Substitution of arginine by histidine at position 134 (H134R) doubled current size by delayed 
Fig. 1 The optogenetic principle: changing the membrane voltage potential of excitable cells. a Activating tools-channelrhodopsins: channelrhodopsin-2 from Chlamydomoas reinhardtii (ChR2) and channelrhodopsin-1 Volvox carteri (VChR1) from nonselective cation channels leading to depolarization of target cells. Silencing tools-ion pumps: archaerhodopsin-3 (Arch) from Halorubrum sodomense works as a proton pump and leads to hyperpolarization of the target cell such as the chloride pump NpHR (NpHR) from Natronomonas pharaonis. b Spectral working properties of lightsensitive membrane proteins
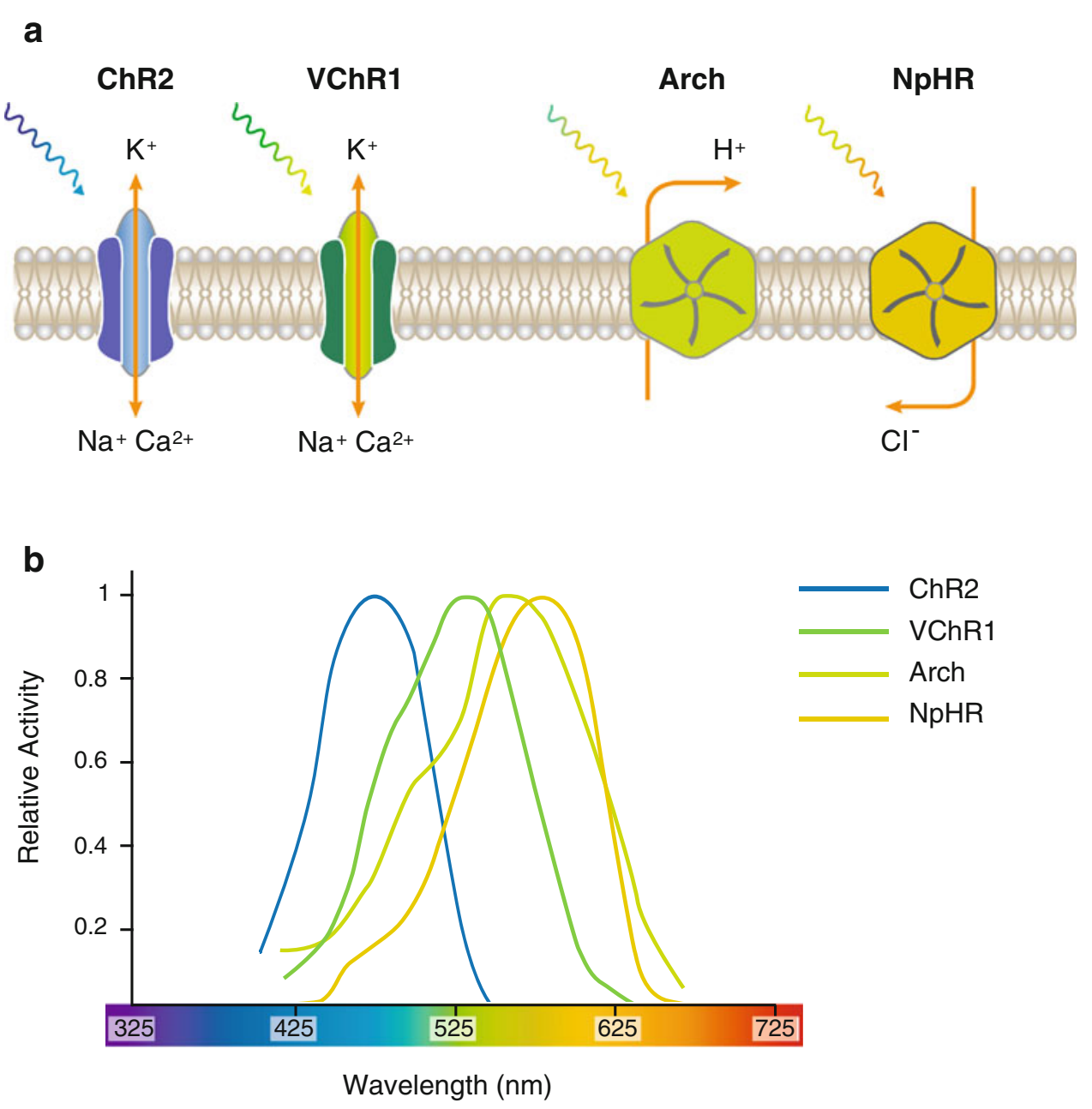

channel closure, but the doubled off-kinetics led to impaired temporal precision (Boyden et al. 2005; Gradinaru et al. 2007; Lin et al. 2009). Wild-type hChR2 works reliably in a frequency ranging from 1 to $20 \mathrm{~Hz}$. In order to improve channelrhodopsin accuracy also in a higher frequency range, site-directed mutated variants of $\mathrm{ChR} 2$ were tested for their optogenetic qualities, identifying CHETA. Mutation at position 123 in CHETA (E123T or A) led to increased steady state-to-peak current ratio and faster offkinetics, resulting in precise spike trains up to $120 \mathrm{~Hz}$. In line with the aforementioned example the advantage of high frequent and temporally precise stimulation was traded against a reduced peak current (Gunaydin et al. 2010). An approach to circumvent loss of current and repetitive spiking fidelity by improving frequency was the generation of chimeric hybrids of ChR1 and ChR2 (ChIEF) with reduced desensitization, stronger currents and reliable spiking beyond $20 \mathrm{~Hz}$ (Lin et al. 2009). After transferring crystallographic observations made in BRs to channelrhodopsins, step-function opsins (SFOs) were generated by site-directed point mutation of the cytosine in position 128 (Berndt et al. 2008; Bamann et al. 2010). Modifying the hypothetical chromophore binding pocket slowed down the photocycle kinetics by means of extending the conducting state up to nearly 2 min for certain mutations (C128S). Thereby, long-time depolarization is induced far beyond the pulse duration of illumination. Inactivation during this period of prolonged activation can be achieved by pulses of $560 \mathrm{~nm}$ light. In a recent publication, C128 mutants have been used for the induction of prolonged depolarization (up to even days after repetitive stimulation) in muscle cells and neurons from Caenorhabditis elegans, thereby triggering long-term behavioral effects and influencing animal development (Schultheis et al. 2011). Similar effects are observed with the D156A mutation in the fourth transmembrane domain (Bamann et al. 2010) and the combination of both SFO mutations resulted in remarkable stability of the active state up to $30 \mathrm{~min}$ (Yizhar et al. 2011b).

Another possibility of long-term manipulation is the targeting of $\mathrm{G}$ protein-mediated intracellular signaling cascades with novel optogenetic tools such as chimeric rhodopsins fused to $G$ protein-coupled receptors also known as optoXRs or RH-CTs. By exchanging the intracellular loops of the native rhodopsin with corresponding ones 
from $\alpha 1$-adrenergic (Opto- $\left.\alpha_{1} \mathrm{AR}\right) / \beta 2$-adrenergic receptors (Opto- $\beta_{2} \mathrm{AR}$ ) or the c-terminal domain of the 5-HT1A receptor $\left(\mathrm{Rh}_{-} \mathrm{CT}_{5-\mathrm{HT} 1 \mathrm{~A}}\right)$, intracellular signaling via PLC or adenylyl cyclase could be elicited (Airan et al. 2009, Oh et al. 2010). In the case of Opto- $\alpha_{1}$ AR light-induced $G_{q}$ protein-mediated inositol triphosphate elevation led to behavioral changes in freely moving mice. However, the need of 11-cis retinal is a problem for the in vivo application of these rhodopsin hybrids. Direct optical control over second messengers and consecutive behavioral changes in drosophila were also achieved by the identification and heterologous expression of directly photoactivated adenylyl cyclcases such as bPAC from the bacterium Beggiatoa sp. (Stierl et al. 2011). Optogenetic manipulation of intracellular signaling allows phasic as well as tonic stimulation, an interesting advantage over pharmacological approaches. Recently another example of rhodopsin optimization was reported by the Bamberg lab. On the search for ChR2 mutants with higher light sensitivity they identified a new principle by indirectly increasing light sensitivity through elevating calcium permeability. As described above for the 123 and 128 mutants higher light sensitivity achieved by increasing the open state of the channel and elevating $\mathrm{Na}^{+}$ influx was traded in for slower response kinetics. By individually replacing each amino acid from Arg115 to Thr139, which are located in the third transmembrane domain, the L132C (CatCh) mutation was identified. CatCh has a 2.6fold higher $\mathrm{Ca}^{2+}$ permeability compared to wild-type ChR2. The activation of voltage-gated $\mathrm{Na}^{+}$channels, which is facilitated by an increase in $\left[\mathrm{Ca}^{2+}\right]_{\mathrm{I}}$, elevates the internal surface potential and thereby indirectly increases light sensitivity. Moreover, the $\mathrm{Ca}^{2+}$-mediated increase in $\mathrm{Na}^{+}$sensitivity results in a faster response kinetics and improved spike reliability of $\mathrm{CatCh}$ in comparison to the wild-type ChR2 (Kleinlogel et al. 2011). Yet long-term tolerability and functionality have to be analyzed in the living mammalian brain, as calcium interference is likely to affect intracellular signaling cascades.

\section{Targeted delivery of optogenetic tools}

For most of the targeting, in vivo viral gene transfer has been effectively used in mice, rats and non human primates, especially adeno-associated viruses (AAV; e.g., Sohal et al. 2009; Carter et al. 2010) lentiviruses (e.g., Adamantidis et al. 2007; Han et al. 2009), and to a lesser extent also herpes simplex virus (HSV; e.g., Covington et al. 2010; Lobo et al. 2010). Advantages of viral expression are a straightforward experimental approach, which takes approximately 6 weeks from virus production to extensive long lasting opsin expression (four more weeks for HSV) and a broad applicableness regarding the subject, ranging from rodents to primates. Depending on the experimental setup either strong ubiquitous promoters such as elongation factor 1-alpha $(\mathrm{EF} 1 \alpha)$, human synapsin, human thymocyte differentiation antigen 1 (Thy-1), a combination of chicken betaactin promoter and cytomegalovirus immediate-early enhancer (CAG) or weaker cell type-specific promoters, for example $\alpha$-calcium/calmodulin-dependent protein kinase II (CamKII $\alpha$ ) can be used (Fig. 2a; Xu et al. 2001; Jakobsson et al. 2003; Dittgen et al. 2004). AAVs are to some extent superior to lentiviruses due to the fact that AAV-based vectors remain episomally while lentiviral vectors are integrated into the host genome. Thus, the expression from lentiviral vectors is prone to influences of the surrounding chromatin and the integration could lead to an undesired disruption of host genes. General drawbacks are a limited packing volume of AAVs and lentiviruses and weak cell type-specific transcriptional promoter activity. For example, the smallest promoter targeting selectively inhibitory neurons is approximately 3 kilobase pairs $(\mathrm{kb})$ in length, which interferes with the maximal capacity of AAVs and lentiviruses, which is about 5 and $8 \mathrm{~kb}$, respectively (Nathanson et al. 2009; Dong et al. 2010). A limitation often seen in experiments using cell type-specific promoters is the need of high irradiance for optimal stimulation of larger brain areas. As light penetration is low in brain tissue, reaching deeper regions optically requires either higher expression levels of the rhodopsin (e.g., by using a strong exogenous promoter as indicated above) or higher levels of light energy. As an alternative to moderately active tissueor cell type-specific promoters, strong conditional rhodopsin expression can be achieved by the use of transgenic cre recombinase driver mice (Fig. 2; Geschwind 2004; Gong et al. 2007). By using a cre-dependent viral construct like AAV-FlEx (Flip-Excision) or AAV-DIO (double floxed inverse open reading frame) driven by a strong promoter such as EF1 $\alpha$ or CAG, cell and tissue specificity is provided by selective cre activity (Fig. 2b; Atasoy et al. 2008; Sohal et al. 2009). An alternative to viral injections is the use of transgenic animals, where rhodopsin expression occurs early in development. Several transgenic mouse lines exist, expressing channelrhodopsin or HR under the panneuronal Thy-1 promoter (Arenkiel et al. 2007; Wang et al. 2007; Zhao et al. 2008) or the glutamatergic Vglut2 promoter (Fig. 2c; Hagglund et al. 2010). In analogy to the abovementioned cre-dependent conditional approach utilizing viral gene delivery systems, a cell type-specific expression could be achieved by using a strong panneuronal promoter such as EF $1 \alpha$ or CAG in combination with the cre-loxP system. Breeding to selective cre driver mice will result in expression of ChR2 or NpHR driven by the panneural promoter, whereas the temporal and spatial expression will depend on the used cre driver line (Fig. 2d). For in vivo cell type-specific opsin expression in utero electroporation has 
a
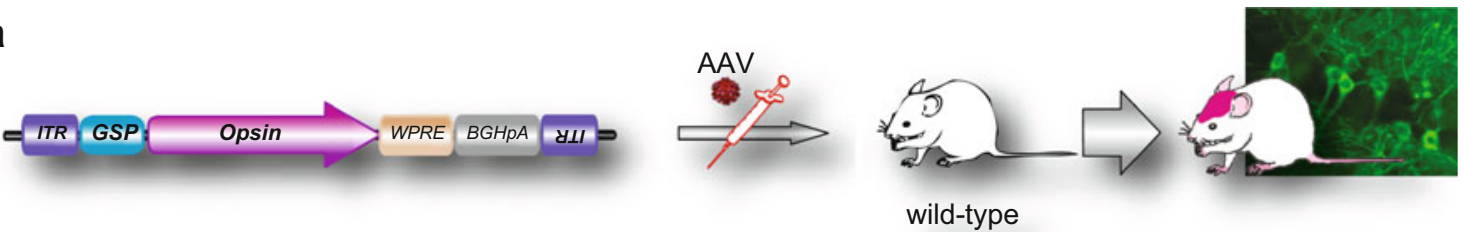

b
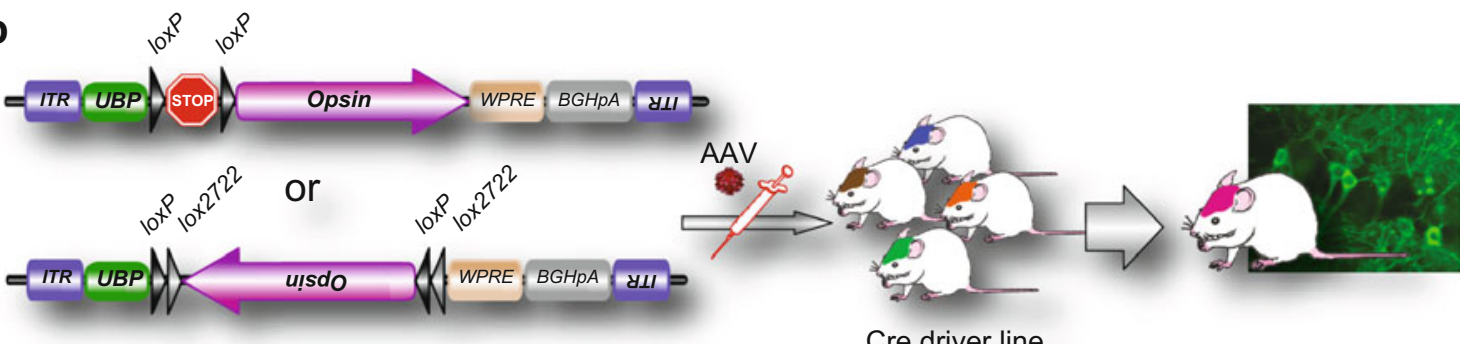

Cre driver line

of interest

C
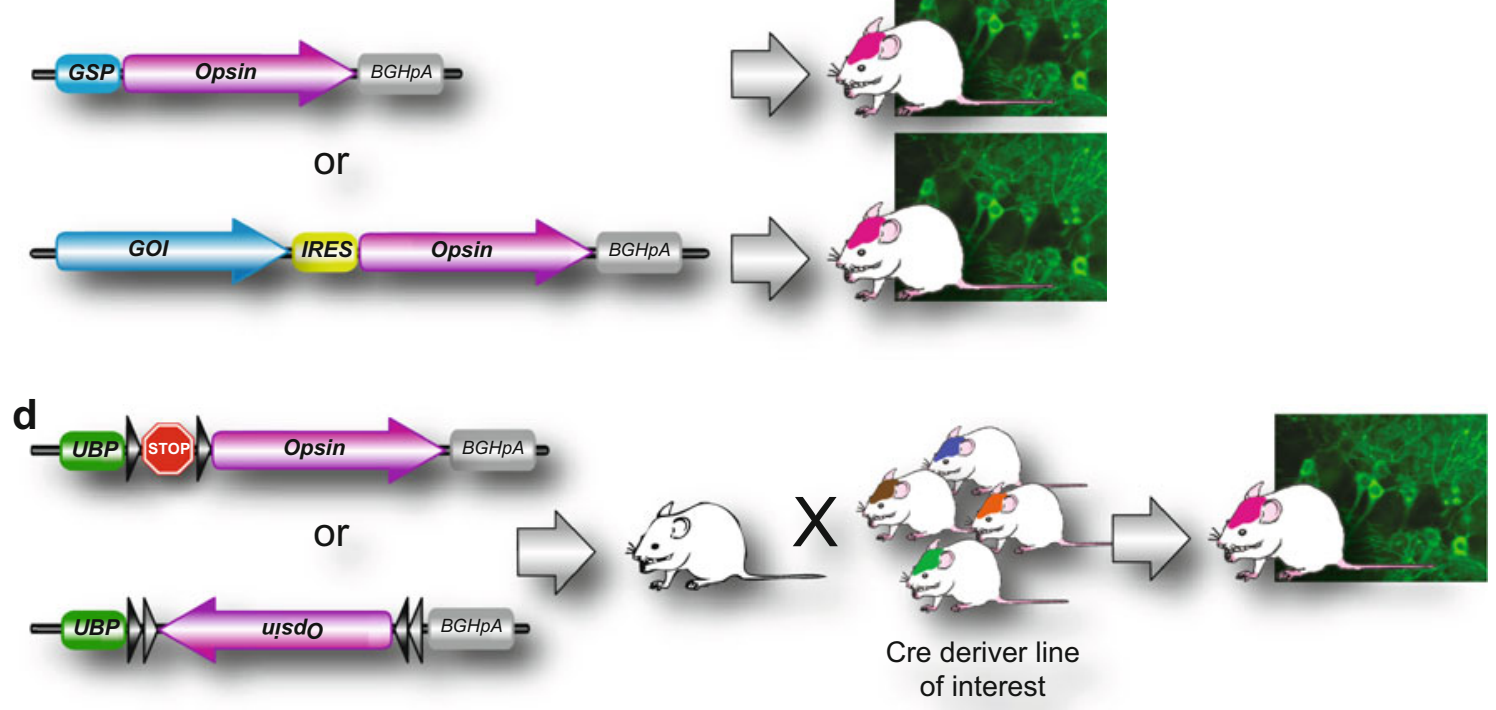

Fig. 2 Targeted delivery of opsins to the mouse brain based on adenoassociated viruses (AAV) or transgenic approaches. a Opsins can be expressed in specific types of neurons or glia using gene-specific promoter elements (e.g., CamKII $\alpha$ ). AAV-based expression vectors integrating such promoter elements are delivered via stereotactic injection into desired brain areas. b Stereotactic injection of AAV vectors, which combine a strong ubiquitous promoter (e.g., Ef $1 \alpha$ or CAG) either with a "STOP" cassette (top) or with an AAV-FIEx/AAV-DIO system (bottom), into specific cre mouse lines will result in a strong opsin expression selectively in neurons expressing the cre recombinase. c Classical transgenesis via pronucleus injection using a gene-specific promoter (top) or targeted knock-in strategies in embryonic stem cells (bottom) will result in a neuron- or glia-specific opsin expression in

been used. Lacking construct size limitations even large cell type-specific promoters can be used to drive expression. Depending on the day of embryonic development various brain areas and cell types can efficiently be targeted transgenic mice. d Alternatively, the combination of a ubiquitous promoter with a "STOP" cassette (top) or with an AAV-FIEx/AAVDIO system (bottom) can be applied also in a transgenic approach either in a random or targeted fashion, e.g., to the ubiquitously expressed ROSA26 locus. Only after breeding to desired cre driver lines a brain region- or cell type-specific expression of opsins will be activated. Mice expressing opsins can be recognized by the highlighted brain and an inset in the background showing hippocampal neurons expressing opsin-GFP fusion protein. $A A V$ adeno-associated virus, $B G H p A$ bovine growth hormone poly A signal, GOI gene of interest, GSP gene-specific promoter, IRES internal ribosomal entry side, ITR inverted terminal repeat, STOP transcriptional terminator, $U B P$ : ubiquitous promoter, WPRE woodchuck hepatitis virus posttranscriptional regulatory element

(Saito 2006; Gradinaru et al. 2007; Navarro-Quiroga et al. 2007; Petreanu et al. 2007). Besides cell type-specific control in different brain areas, circuit-specific targeting may be desirable to distinguish more precisely between neurons, 
which, although carrying the same cell-specific set of genetic markers, are heterogeneous regarding their afferent or efferent influences. By fusing cre recombinase to axonally transported proteins such as wheat germ agglutinin (WGA) and tetanus toxin fragment C (TTC) or using idiosyncratic antero-/retrograde viral axonal delivery, circuit connectivity can be analyzed by optogenetics in a transneuronal fashion. This transcellular approach in combination with conditional cre-dependent expression vectors represents a versatile tool for circuit mapping independent of the use of cre animals, extending the cell type-specific optogenetic approach to animals such as rats and primates, which have not been amenable to large-scale genetic manipulation (Gradinaru et al. 2010).

\section{Optogenetics is compatible with a plethora of functional readouts}

The major advantage of optogenetics, besides genetic targeting, is stimulation with light, as it offers the possibility of simultaneous on-site electrical measurement. Depending on the desired resolution, optogenetics can be combined with a variety of readouts. For in vitro proof-of-concept experiments the most widely used methods are whole-cell patch clamp and field potential recordings in combination with optical illumination in brain slices (for example Nagel et al. 2003; Boyden et al. 2005; Deisseroth et al. 2006; Zhang et al. 2007a, b). To study neural activity beyond single cells on a network level calcium imaging can be used as a multisite indirect measurement of action potential activity in a full optical approach (Knopfel et al. 2006). The first example of postsynaptic calcium imaging following lightinduced action potentials in ChR2-targeted presynaptic axons was demonstrated by Zhang and Oertner (2007) to study plasticity at single-synapse level. By using a spectrally compatible dye (Fluo-5F) and two-photon excitation at $810 \mathrm{~nm}$ in rat hippocampal slice cultures targeted with ChR2-tdimer2, synaptic contacts between labeled cells could be identified by imaging optically induced spinal calcium release. In addition, long-term potentiation of prevalent synaptic connections was induced (Zhang and Oertner 2007). An all-optical approach was also applied in the initial description of bidirectional optical control of neural circuits. After lentiviral transduction of murine acute cortical slices with CaMKII $\alpha:$ ChR2-mCherry and EF1 $\alpha:$ NpHREYFP Fura-2 calcium imaging was used to measure the effects of optical excitation and inhibition (Zhang et al. 2007a). Because of its UV-shifted spectral properties (excitation maximum at $340 \mathrm{~nm}$ ) Fura-2 has been successfully used in concert with $\mathrm{ChR} 2$ (excitation maximum at $470 \mathrm{~nm}$ ), NpHR (excitation maximum at $590 \mathrm{~nm}$ ) and the OptoXRs (excitation maximum at $500 \mathrm{~nm}$; Airan et al.
2009). Yet, although spectrally overlapping, genetically encoded calcium sensors such as G-CaMP can be applied in concert with ChR2. In a technically elegant study Guo et al. (2009) combined in vivo optical stimulation of ChR2 wavelength with simultaneous calcium imaging at $488 \mathrm{~nm}$ for functional connectivity mapping in C. elegans neurons. By separating an epifluorescent high-power stimulation path for ChR2 activation from a low-intensity laser light imaging path for G-CaMP fluorescence, unspecific ChR2 activation during imaging at $488 \mathrm{~nm}$ could be avoided although ChR2 has its peak activation at $470 \mathrm{~nm}$ (Guo et al. 2009, see also Fig. 1). Laser scanning photostimulation (LSPS) has previously also been used in combination with glutamate uncaging and whole-cell recordings to analyze synaptic connectivity in brain slices (Katz and Dalva 1994; Shepherd and Svoboda 2005; Svoboda and Yasuda 2006). By exchanging glutamate uncaging against light activation through targeted axonal photosensitivity via ChR2, the group of Svoboda developed ChR2-assisted circuit mapping (CRACM; Petreanu et al. 2007). Using in utero electroporation in mice layer, $2 / 3$ cortical neurons were targeted with ChR2-venus and photostimulation was performed throughout a grid covering the entire depth of the cortex. Whole-cell current clamp recordings of fluorescent ChR2 positive cells revealed their depolarization and detected action potentials after perisomatic and axonal LSPS. Mapping postsynaptic targets of $\mathrm{L} 2 / 3$ neurons in several cortical layers in the ipsi- and contralateral hemisphere indicated laminar specificity of local and long-range cortical projections (Petreanu et al. 2007). A modified approach (sCRACM) was used to study the subcellular organization of excitatory pyramidal neurons. Local glutamate release was measured after LSPS in conditions blocking action potentials. EPSPs as a measure of light-induced activation were detected only in the case of overlap between the recorded cell and ChR2-targeted presynaptic axons. Interestingly, subcellular mapping of neural circuitry by sCRACM revealed that the structural connectivity of neurons, as indicated by overlap of axons and dendrites, is not always reflected by their connection on a functional level (Petreanu et al. 2009). To study whole circuit properties voltage-sensitive dyes (VSD) can be applied in brain slices for an all-optical approach. As VSDs change their light emission properties in a voltage-dependent and most notably in a millisecond time scale they are potentially well suited to match the high temporal resolution achieved by optogenetics (Grinvald and Hildesheim 2004). Although compatibility can be achieved with spectrally separated infrared dyes such as RH-155 and VSD imaging following optical stimulation has been established successfully, it has rarely been used experimentally up to now, most probably due to a less favorable signal-to-noise ratio in comparison to calcium imaging (Airan et al. 2007; Zhang et al. 2010). 
Another example for the study of macrocircuits and global in vivo mapping is optical stimulation in combination with high-resolution fMRI. Lee and colleagues showed in a first publication that blood oxygenation level-dependent (BOLD) signals similar to classical stimulus-evoked BOLD fMRI responses could be elicited optically. This effect was seen not only locally at the expression site of ChR2 in M1 CaMKII $\alpha$ positive excitatory neurons, but also in distinct thalamic neurons defined by the corticofugal axonal projections (Lee et al. 2010). In a reverse approach optical stimulation of $\mathrm{ChR} 2$ expressing cortico-thalamic projection fibers at the level of the thalamus was sufficient to drive not only local thalamic BOLD signals, but also cortical signals, most probably in an antidromic axosomatic manner. "OptofMRI" or "ofMRI" has also been used to identify downstream targets of the primary sensory cortex (SI). Optical stimulation of a ChR2-targeted subpopulation of SI pyramidal cells evoked local BOLD signals and also in functionally connected network regions, with differences in awake compared to anesthetized mice (Desai et al. 2011). Even though widely hypothesized before, these experiments indicate a most likely causal link between local neuronal excitation and positive hemodynamic responses, although the generation of BOLD signals may have a more complex nature. However, functional mapping using optogenetics in combination with fMRI not only integrates cell type specificity and anatomical conjunction, but can also be used to functionally dissect brain circuitries based on their connection topology (Leopold 2010). For global measurements of brain activity in living animals, electroencephalography (EEG) has been combined with optogenetic stimulation. In a first experiment Adamantidis et al. $(2007,2010)$ identified the effect of hypocretin-producing neurons in the lateral hypothalamus on sleep to wake transition by analyzing sleep recordings of mice with chronically implanted EEG electrodes. In a bidirectional in vivo approach using eNpHR and ChR2 the same group studied the effect of locus coeruleus neurons on wakefulness by applying EEG and in vivo microdialysis as a functional readout (Carter et al. 2010). For in vivo extracellular recording upon targeted optical stimulation, a device called "optrode" was created fusing a stimulating fiberoptic with a recording electrode (Gradinaru et al. 2007, 2009). Constant technical development even allows simultaneous recordings at multiple sites in the living animal (Zhang et al. 2009; Royer et al. 2010). The foundation for using optogenetics in freely moving rodents was set by Aravanis et al. (2007). Via a lightweight, flexible optical fiber called optical neural interface (ONI) excitatory motor cortex neurons could selectively be activated in rats and mice as measured by their whisker movement. Several successive studies focused on more complex behavioral paradigms as readouts for optogenetical manipulation such as motor behavior in animal models of Parkinson's disease (Gradinaru et al. 2009; Kravitz et al. 2010), reward motivated behavior and addiction (Airan et al. 2009; Tsai et al. 2009; Witten et al. 2010; Stuber et al. 2011), fear conditioning and anxiety (Ciocchi et al. 2010; Johansen et al. 2010; Tye et al. 2011) and other cerebral targets such as prefrontal cortex or hypothalamus for the study of psychiatric diseases and aggressive behavior (Covington et al. 2010; Lin et al. 2011; Yizhar et al. 2011a, b).

\section{From microbes to model organisms and beyond}

Optogenetics is applicable to diverse species and animal models. For the initial functional characterization of ChR1 and ChR2 a host model was applied that had previously been successfully used for different rhodopsins. Expression of ChR 1 and ChR2 in oocytes from Xenopus laevis in the presence of all-trans retinal was the first example of functional heterologous channelrhodopsin expression outside of algae (Nagel et al. 2002, 2003). At that moment the equation was: $\mathrm{CHOP} 1$ or $2+$ retinal $=\mathrm{ChR} 1$ or $\mathrm{ChR} 2$, as the photoreceptor system from Chlamydomonas reinhardtii was thought to be composed of channelopsin (from a cDNA originally named CHOP1 and CHOP2 but also termed Chlamyopsin, Cop3 or Cop4) and all-trans retinal (Nagel et al. 2003). Deisseroth and colleagues redid the math and prove that "CHOP2" successfully worked in rat hippocampal primary neurons after lentiviral transduction without adding all-trans retinal at all (although the culture media contained little amounts of the precursor retinyl acetate). By this, ChR2 was established as a new one-component functional tool for neuroscience in mammals neither requiring the substitution of any synthetic chemical substrate nor genetic orthogonality between the rhodopsin and the targeted host organism, even more important as there is no mammalian analog of the algal gene CHOP2 (Boyden et al. 2005). The first in vivo applications in living animals were put into practice in parallel by $\mathrm{Li}$ et al. (2005) and Nagel et al. (2005). Transgenic expression of ChR2 specifically in cholinergic motorneurons of $C$. elegans allowed to elicit behavioral responses via muscular contractions by blue light illumination (Nagel et al. 2005). Bidirectional, both inhibitory and excitatory in vivo control of spontaneous chick spinal cord activity was performed in chicken embryos after in ovo electroporating and transient expression of ChR2 and vertebrate Ro4, respectively ( $\mathrm{Li}$ et al. 2005). Another example of bidirectional in vivo control of C. elegans locomotion was achieved after simultaneous expression of $\mathrm{ChR} 2$ and NpHR using the muscle-specific myosin promoter Pmyo-3 (Zhang et al. 2007a). As mentioned above $C$. elegans has also been used for an in vivo all-optical interrogation of neural circuits using ChR2 and 
G-CaMP (Guo et al. 2009). The first use of optogenetics in zebrafish revealed that activation of zebrafish trigeminal neurons by ChR2 induces escape behavior even upon single spikes, as published by Douglass et al. (2008). By using Gal4 enhancer trapping in zebrafish, transgenic animals can be generated in a feasible way (Scott et al. 2007). The Bayer lab efficiently used the GAL4/UAS system to selectively express ChR2 and NpHR in specific neuronal subpopulations of zebrafish larvae. Owing to the transparent nature of the animal in vivo functional mapping at a single neuron resolution was performed dissecting neuronal populations involved in swim behavior, saccade generation as well cardiac development and function (Arrenberg et al. 2009, 2010; Schoonheim et al. 2010). GAL4/UAS was also used to introduce ChR2 into specific subsets of neuronal populations (painless) in Drosophila melanogaster by crossing transgenic UAS-ChR2 flies with neuronspecific Gal4 transgenic lines (Zhang et al. 2007c). Optical stimulation of nociceptive neurons in transgenic larvae by $\mathrm{ChR} 2$ induced behavioral responses. However, it has to be taken into account that D. melanogaster and zebrafish contain hydroxyretinal which does not enter the ChR or HR binding sites making a substitution of all-trans retinal necessary (for example by food supplement). Moreover, interpretation of behavioral data in D. melanogaster can be conflicting as the animal has an innate behavioral light response (Pulver et al. 2009). The species most widely investigated with optogenetic technologies is the mouse. This is largely owing to the vast availability of transgenic cre driver lines, which can readily be combined with cre-dependent viral vectors in order to facilitate strong cell-/tissue-specific rhodopsin expression (Fig. 2). As mentioned above, in mice also classical transgenic approaches have been applied to express ChR2 and NpHR under the control of the Thy-1 promoter. Arenkiel et al. (2007) showed strong and functional, regionally restricted, channelrhodopsin expression in Thy 1::ChR2-EYFP mouse strains. By presynaptic optical manipulation of targeted cells in the bulbar-cortical circuit of the olfactory system they highlighted the potential of optogenetics for complex circuit analysis in brain slices and in vivo. Wang et al. (2007) used transgenic Thy1-ChR2YFP mice for the mapping of functional connectivity in the neural circuitry of cortical layer VI neurons. In order to study the role of fast spiking parvalbumin interneurons in the generation of gamma oscillations, Thy $1:$ ChR2-EYFP mice were analyzed in combination with a cre-dependent approach (Sohal et al. 2009). This animal model in combination with a cell type-specific lentiviral approach was also successfully used in the systematic dissection of circuits and deciphering of potential targets related to deep brain stimulation in a Parkinson mouse model (Gradinaru et al. 2009). Hagglund and colleagues used BAC transgenesis to express ChR2-EYFP under the control of the vesicular glu- tamate receptor two promoter. These transgenic mice express ChR2 in glutamatergic neurons of the hindbrain and spinal cord. By optical stimulation of the lumbar region of the spinal cord and also the caudal hindbrain rhythm generation was observed, suggesting a role of glutamatergic neurons in central pattern generators of locomotion (Hagglund et al. 2010). Various examples in nematodes, mice and rats have demonstrated a direct effect of in vivo optogenetic stimulation on neuronal activity and behavioral responses (Nagel et al. 2005; Gradinaru et al. 2009; Tsai et al. 2009; Lee et al. 2010). Yet optical control of cortical circuits in higher organisms might be more complex: the first optogenetic approach in primates was performed in the rhesus macaque. Boyden and colleagues targeted specifically excitatory neurons of the frontal cortex by stereotactic lentiviral gene delivery of ChR2-GFP driven by the CamKII $\alpha$ promoter and recorded neuronal activity after simultaneous optical stimulation via an optrode (Han et al. 2009). Besides showing the feasibility and safety of optogenetics in primates and thereby implementing a potential clinical translation for the use in humans, the experiments showed a slightly discouraging, but seminal, result. Although ChR2 was targeted specifically to excitatory neurons a significant proportion of recorded cells showed decreased activity. This finding was previously also observed in transgenic Thy1-ChR2 mice and is comparable to heterogeneous tissue activation in the case of electrical stimulation. Thus, targeting cortical circuits in a cell type-specific manner cannot precisely predict a specific psychological response, respectively, behavioral or clinical outcome. The impact of optogenetic manipulation on cortical circuitries seems to be heavily dependent on the neural network, in which the target cells are embedded. Nevertheless, the results indicate important aspects for therapeutic options and suggest lentiviral rhodopsin delivery as a well immuno-tolerated method for a putative application in humans.

\section{Potential clinical applications of optoprosthetics}

Recent publications underpin the possible role of optogenetics as a potential future therapeutic application. For example, electrical peripheral nerve stimulation has been used as an experimental treatment of patients with paralysis and muscle disease. A major drawback is random or reverse muscle recruitment by heterogeneous tissue excitation, resulting in high fatigability. Thy-1::ChR2YFP transgenic mice express ChR2-YFP in both the central and peripheral nervous system as well as in lower motor and dorsal root ganglion neurons. By an optical approach motor units can be recruited in an orderly manner favoring small, slow muscle fibers in comparison to random recruitment by electrical stimulation. This results in a markedly enhanced 
functional performance as muscle fatigability is strongly reduced by a more physiological recruitment pattern via optical stimulation. Taking into account recent advances in human gene therapy the authors point out an eventual therapeutic use of optogenetics as neuroprosthetics and suggest $\mathrm{NpHR}$ in the treatment of spastic movement disorders (Llewellyn et al. 2010). Another promising example of optical control replacing electrical stimulation is light-induced stimulation of the heart muscle. Bruegmann et al. (2010) transferred the optogenetic principle from neurons to cardiomyocytes. A ChR2-EYFP construct driven by the CAG promoter was electroporated into embryonic stem cells (ESCs). After ESC differentiation into cardiomyocytes ChR2 expression was limited to the cell membrane and pulsed in vitro optical stimulation triggered action potential-induced contractions with intercellular electrical spreading. The authors also generated transgenic CAG-ChR2-EYFP mice that showed robust rhodopsin expression in atrial and ventricular cardiomyoctes. By illuminating an area of only $0.05-0.2 \mathrm{~mm}$ with pulses as short as $1 \mathrm{~ms}$, reliable action potentials were generated in a minimally delayed 1:1 manner in vitro and in vivo, allowing fast optical pacing limited only by the natural refractoriness of the cardiac cells. Thus, optogenetics could serve as an analytical tool for the study of pacemaking and arrhythmia in cardiology with a high potential for therapeutic use. There are several putative clinical applications of optogenetics also in neurodegenerative disorders. A recent work from Stroh et al. (2011) focuses on a restorative approach. Mouse ESCs were transduced in vitro via lentiviruses to express ChR2-YFP under the EF $1 \alpha$ promoter. After a retinoic acid-based differentiation protocol, targeted cells were viable and electrophysiologically mature, similar to native cells. After FACS sorting ChR2-YFP expressing cells were transplanted into rat motor cortex and reacted toward blue light illumination after integration into the host environment. Depolarization and direct $\mathrm{Ca}^{2+}$ influx via light-gated membrane proteins such as ChR2 could serve as a new tool for stem cell differentiation into neural and neuronal cells in vitro and in vivo, as various facts indicate an important role of $\mathrm{Ca}^{2+}$ dependent cellular processes driving differentiation (e.g., D'Ascenzo et al. (2006). As functional integration of the transplant is the major goal of regenerative medicine, optogenetically induced differentiation, compared to unspecific chemically or electrically based protocols, just affects the genetically targeted graft cells within a heterogeneous cellular host environment, reducing undesirable side effects such as cell death or tumor growth (Stroh et al. 2011). In a previous study neurons derived from human ESCs were transduced with ChR2-mCherry and mature neurons were analyzed for synaptic integration and functional connectivity of the targeted graft cells into the host circuitry of immunodepressed neonatal SCID mice (Weick et al. 2010). In vitro postmitotic neurons, both glutamatergic and GABAergic, showed typical electrophysiological responses upon illumination. When transplanted, ChR2 positive matured neurons not only displayed spontaneous action potentials and postsynaptic currents (PSCs) as a proof of input-specific graft integration, but furthermore, adjacent ChR2-negative cells likewise displayed PSCs upon light stimulation, indicating graft to host microcircuit connectivity also in an outputspecific manner. By generating a pluripotent human ESC line, expressing ChR2-mCherry constitutively under the synapsin promoter, the authors could improve several drawbacks of viral based approaches such as low transduction efficiency. Yet further research is necessary to establish optogenetics as a standard examination and manipulation tool of functional graft to host integration and circuit plasticity in the context of stem cell based neuroregenerative strategies. Another example for a clinical application could be vision restoration in human subjects with retinal degeneration. ChR2- and NpHR-based approaches would, due to their simple monocomponent working principle with good immune compatibility, cell type specificity and high spatial resolution, compete with electrical stimulation in their ability of restoring photosensitivity. In blind mice lacking retinal photoreceptors ( $\mathrm{rd} 1$ or Pde6b ${ }^{\text {rd1 }}$ mouse model, Bowes et al. 1990) photosensitivity was restored by heterologous expression of ChR2, either by transducing inner retinal neurons in a non-selective viral based strategy or by in vivo electroporating exclusively $\mathrm{ON}$ bipolar retinal cells using a specific promoter sequence (Bi et al. 2006, Lagali et al. 2008). Positive changes in a behavioral readout indicated improved vision and suggest the use of optogenetics in a translational approach also in humans. A major step toward applications in vivo, especially for therapeutic use in humans, would be the employment of highly light-sensitive rhodopsins with specifically defined response kinetics supporting optical control at a cell type-specific resolution. In general optogenetics would significantly benefit from ChRs with larger conductance and higher selectivity for $\mathrm{Ca}^{2+}, \mathrm{Na}^{+}$or $\mathrm{K}^{+}$in combination with appropriate color and kinetics.

\section{Conclusions}

Optogenetics has matured within a few years into a stateof-the-art technology. This technological breakthrough allows to tackle biological questions, which were previously out of reach of our imaginations. The major impact of optogenetics in the upcoming years will most likely be dominated by approaches fundamentally increasing our comprehension of neural, as well as non-neural systems, on a circuit level. A deeper understanding of these intricate regulatory networks might unravel novel targets within 
such complex circuits, which could be suitable for therapeutic intervention. Optogenetics has demonstrated its enormous potential in animal models including nonhuman primates and thereby has raised considerable expectations with respect to future clinical applications. However, whether optogenetics will cross the Rubicon and will be amenable to application in human patients will primarily depend on similar obstacles that gene therapy has been struggling with all along, namely efficient and safe gene delivery strategies.

Open Access This article is distributed under the terms of the Creative Commons Attribution Noncommercial License which permits any noncommercial use, distribution, and reproduction in any medium, provided the original author(s) and source are credited.

\section{References}

Adamantidis AR, Zhang F, Aravanis AM, Deisseroth K, de Lecea L (2007) Neural substrates of awakening probed with optogenetic control of hypocretin neurons. Nature 450:420-424

Adamantidis AR, Carter MC, de Lecea L (2010) Optogenetic deconstruction of sleep-wake circuitry in the brain. Front Mol Neurosci 2:31

Airan RD, Hu ES, Vijaykumar R, Roy M, Meltzer LA, Deisseroth K (2007) Integration of light-controlled neuronal firing and fast circuit imaging. Curr Opin Neurobiol 17:587-592

Airan RD, Thompson KR, Fenno LE, Bernstein H, Deisseroth K (2009) Temporally precise in vivo control of intracellular signalling. Nature 458:1025-1029

Aravanis AM, Wang LP, Zhang F, Meltzer LA, Mogri MZ, Schneider MB, Deisseroth K (2007) An optical neural interface: in vivo control of rodent motor cortex with integrated fiberoptic and optogenetic technology. J Neural Eng 4:S143-S156

Arenkiel BR, Peca J, Davison IG, Feliciano C, Deisseroth K, Augustine GJ, Ehlers MD, Feng G (2007) In vivo light-induced activation of neural circuitry in transgenic mice expressing channelrhodopsin-2. Neuron 54:205-218

Arrenberg AB, Del BF, Baier H (2009) Optical control of zebrafish behavior with halorhodopsin. Proc Natl Acad Sci USA 106:17968-17973

Arrenberg AB, Stainier DY, Baier H, Huisken J (2010) Optogenetic control of cardiac function. Science 330:971-974

Atasoy D, Aponte Y, Su HH, Sternson SM (2008) A FLEX switch targets Channelrhodopsin-2 to multiple cell types for imaging and long-range circuit mapping. J Neurosci 28:7025-7030

Bamann C, Gueta R, Kleinlogel S, Nagel G, Bamberg E (2010) Structural guidance of the photocycle of channelrhodopsin-2 by an interhelical hydrogen bond. Biochemistry 49:267-278

Beja O, Aravind L, Koonin EV, Suzuki MT, Hadd A, Nguyen LP, Jovanovich SB, Gates CM, Feldman RA, Spudich JL, Spudich EN, DeLong EF (2000) Bacterial rhodopsin: evidence for a new type of phototrophy in the sea. Science 289:1902-1906

Berndt A, Yizhar O, Gunaydin LA, Hegemann P, Deisseroth K (2008) Bi-stable neural state switches. Nat Neurosci 12:229-234

Berndt A, Schoenenberger P, Mattis J, Tye KM, Deisseroth K, Hegemann P, Oertner TG (2011) High-efficiency channelrhodopsins for fast neuronal stimulation at low light levels. Proc Natl Acad Sci USA 108:7595-7600

Bi A, Cui J, Ma YP, Olshevskaya E, Pu M, Dizhoor AM, Pan ZH (2006) Ectopic expression of a microbial-type rhodopsin restores visual responses in mice with photoreceptor degeneration. Neuron 50:23-33
Bowes C, Li T, Danciger M, Baxter LC, Applebury ML, Farber DB (1990) Retinal degeneration in the rd mouse is caused by a defect in the beta subunit of rod cGMP-phosphodiesterase. Nature 347:677-680

Boyden ES, Zhang F, Bamberg E, Nagel G, Deisseroth K (2005) Millisecond-timescale, genetically targeted optical control of neural activity. Nat Neurosci 8:1263-1268

Bruegmann T, Malan D, Hesse M, Beiert T, Fuegemann CJ, Fleischmann BK, Sasse P (2010) Optogenetic control of heart muscle in vitro and in vivo. Nat Methods 7:897-900

Carter ME, Yizhar O, Chikahisa S, Nguyen H, Adamantidis A, Nishino S, Deisseroth K, de Lecea L (2010) Tuning arousal with optogenetic modulation of locus coeruleus neurons. Nat Neurosci 13:1526-1533

Chow BY, Han X, Dobry AS, Qian X, Chuong AS, Li M, Henninger MA, Belfort GM, Lin Y, Monahan PE, Boyden ES (2010) Highperformance genetically targetable optical neural silencing by light-driven proton pumps. Nature 463:98-102

Ciocchi S, Herry C, Grenier F, Wolff SB, Letzkus JJ, Vlachos I, Ehrlich I, Sprengel R, Deisseroth K, Stadler MB, Muller C, Luthi A (2010) Encoding of conditioned fear in central amygdala inhibitory circuits. Nature 468:277-282

Covington HE III, Lobo MK, Maze I, Vialou V, Hyman JM, Zaman S, LaPlant Q, Mouzon E, Ghose S, Tamminga CA, Neve RL, Deisseroth K, Nestler EJ (2010) Antidepressant effect of optogenetic stimulation of the medial prefrontal cortex. J Neurosci 30:1608216090

D’ Ascenzo M, Piacentini R, Casalbore P, Budoni M, Pallini R, Azzena GB, Grassi C (2006) Role of L-type Ca2+ channels in neural stem/progenitor cell differentiation. Eur J Neurosci 23:935-944

Deisseroth K, Feng G, Majewska AK, Miesenbock G, Ting A, Schnitzer MJ (2006) Next-generation optical technologies for illuminating genetically targeted brain circuits. J Neurosci 26:10380-10386

Desai M, Kahn I, Knoblich U, Bernstein J, Atallah H, Yang A, Kopell N, Buckner RL, Graybiel AM, Moore CI, Boyden ES (2011) Mapping brain networks in awake mice using combined optical neural control and fMRI. J Neurophysiol 105:1393-1405

Dittgen T, Nimmerjahn A, Komai S, Licznerski P, Waters J, Margrie TW, Helmchen F, Denk W, Brecht M, Osten P (2004) Lentivirusbased genetic manipulations of cortical neurons and their optical and electrophysiological monitoring in vivo. Proc Natl Acad Sci USA 101:18206-18211

Dong B, Nakai H, Xiao W (2010) Characterization of genome integrity for oversized recombinant AAV vector. Mol Ther 18:87-92

Douglass AD, Kraves S, Deisseroth K, Schier AF, Engert F (2008) Escape behavior elicited by single, channelrhodopsin-2-evoked spikes in zebrafish somatosensory neurons. Curr Biol 18:1133-1137

Geschwind D (2004) GENSAT: a genomic resource for neuroscience research. Lancet Neurol 3:82

Gong S, Doughty M, Harbaugh CR, Cummins A, Hatten ME, Heintz N, Gerfen CR (2007) Targeting Cre recombinase to specific neuron populations with bacterial artificial chromosome constructs. J Neurosci 27:9817-9823

Govorunova EG, Spudich EN, Lane CE, Sineshchekov OA, Spudich JL (2011) New channelrhodopsin with a red-shifted spectrum and rapid kinetics from Mesostigma viride. MBio 2(3):e00115-11

Gradinaru V, Thompson KR, Zhang F, Mogri M, Kay K, Schneider MB, Deisseroth K (2007) Targeting and readout strategies for fast optical neural control in vitro and in vivo. J Neurosci 27:1423114238

Gradinaru V, Thompson KR, Deisseroth K (2008) eNpHR: a Natronomonas halorhodopsin enhanced for optogenetic applications. Brain Cell Biol 36:129-139

Gradinaru V, Mogri M, Thompson KR, Henderson JM, Deisseroth K (2009) Optical deconstruction of parkinsonian neural circuitry. Science 324:354-359 
Gradinaru V, Zhang F, Ramakrishnan C, Mattis J, Prakash R, Diester I, Goshen I, Thompson KR, Deisseroth K (2010) Molecular and cellular approaches for diversifying and extending optogenetics. Cell 141:154-165

Grinvald A, Hildesheim R (2004) VSDI: a new era in functional imaging of cortical dynamics. Nat Rev Neurosci 5:874-885

Gunaydin LA, Yizhar O, Berndt A, Sohal VS, Deisseroth K, Hegemann P (2010) Ultrafast optogenetic control. Nat Neurosci $13: 387-392$

Guo ZV, Hart AC, Ramanathan S (2009) Optical interrogation of neural circuits in Caenorhabditis elegans. Nat Methods 6:891-896

Hagglund M, Borgius L, Dougherty KJ, Kiehn O (2010) Activation of groups of excitatory neurons in the mammalian spinal cord or hindbrain evokes locomotion. Nat Neurosci 13:246-252

Han X, Boyden ES (2007) Multiple-color optical activation, silencing, and desynchronization of neural activity, with single-spike temporal resolution. PLoS One 2:e299

Han X, Qian X, Bernstein JG, Zhou HH, Franzesi GT, Stern P, Bronson RT, Graybiel AM, Desimone R, Boyden ES (2009) Millisecond-timescale optical control of neural dynamics in the nonhuman primate brain. Neuron 62:191-198

Han X, Chow BY, Zhou H, Klapoetke N, Boyden E et al (2011) A high-light sensitivity optical neural silencer: development and application to optogenetic control of nun-human primate cortex. Front Sys Neurosci 5:1-8

Harz H, Hegemann P (1991) Rhodopsin-regulated calcium currents in Chlamydomonas. Nature 351:489-491

Holland EM, Braun FJ, Nonnengässer C, Harz H, Hegemann P (1996) The nature of rhodopsin-triggered photocurrents in Chlamydomonas. I. Kinetics and influence of divalent ions. Biophys $\mathrm{J}$ 70:924-931

Ishizuka T, Kakuda M, Araki R, Yawo H (2006) Kinetic evaluation of photosensitivity in genetically engineered neurons expressing green algae light-gated channels. Neurosci Res 54:85-94

Jakobsson J, Ericson C, Rosenqvist N, Lundberg C (2003) Lentiviral vectors. Int Rev Neurobiol 55:111-122

Johansen JP, Hamanaka H, Monfils MH, Behnia R, Deisseroth K, Blair HT, LeDoux JE (2010) Optical activation of lateral amygdala pyramidal cells instructs associative fear learning. Proc Natl Acad Sci USA 107:12692-12697

Katz LC, Dalva MB (1994) Scanning laser photostimulation: a new approach for analyzing brain circuits. J Neurosci Methods 54:205218

Kleinlogel S, Feldbauer K, Dempski RE, Fotis H, Wood PG, Bamann C, Bamberg E (2011) Ultra light-sensitive and fast neuronal activation with the $\mathrm{Ca}(2)+-$ permeable channelrhodopsin $\mathrm{CatCh}$. Nat Neurosci 14:513-518

Knopfel T, ez-Garcia J, Akemann W (2006) Optical probing of neuronal circuit dynamics: genetically encoded versus classical fluorescent sensors. Trends Neurosci 29:160-166

Kravitz AV, Freeze BS, Parker PR, Kay K, Thwin MT, Deisseroth K, Kreitzer AC (2010) Regulation of parkinsonian motor behaviours by optogenetic control of basal ganglia circuitry. Nature 466:622626

Lagali PS, Balya D, Awatramani GB, Munch TA, Kim DS, Busskamp V, Cepko CL, Roska B (2008) Light-activated channels targeted to $\mathrm{ON}$ bipolar cells restore visual function in retinal degeneration. Nat Neurosci 11:667-675

Lee JH, Durand R, Gradinaru V, Zhang F, Goshen I, Kim DS, Fenno LE, Ramakrishnan C, Deisseroth K (2010) Global and local fMRI signals driven by neurons defined optogenetically by type and wiring. Nature 465:788-792

Leopold DA (2010) Neuroscience: fMRI under the spotlight. Nature 465:700-701

Li X, Gutierrez DV, Hanson MG, Han J, Mark MD, Chiel H, Hegemann P, Landmesser LT, Herlitze S (2005) Fast noninvasive activation and inhibition of neural and network activity by vertebrate rhodopsin and green algae channelrhodopsin. Proc Natl Acad Sci USA 102:17816-17821

Lin JY, Lin MZ, Steinbach P, Tsien RY (2009) Characterization of engineered channelrhodopsin variants with improved properties and kinetics. Biophys J 96:1803-1814

Lin D, Boyle MP, Dollar P, Lee H, Lein ES, Perona P, Anderson DJ (2011) Functional identification of an aggression locus in the mouse hypothalamus. Nature 470:221-226

Llewellyn ME, Thompson KR, Deisseroth K, Delp SL (2010) Orderly recruitment of motor units under optical control in vivo. Nat Med 16:1161-1165

Lobo MK, Covington HE III, Chaudhury D, Friedman AK, Sun H, mez-Werno D, Dietz DM, Zaman S, Koo JW, Kennedy PJ, Mouzon E, Mogri M, Neve RL, Deisseroth K, Han MH, Nestler EJ (2010) Cell type-specific loss of BDNF signaling mimics optogenetic control of cocaine reward. Science 330:385-390

Matsuno-Yagi A, Mukohata Y (1977) Two possible roles of bacteriorhodopsin; a comparative study of strains of Halobacterium halobium differing in pigmentation. Biochem Biophys Res Commun 78:237-243

Nagel G, Ollig D, Fuhrmann M, Kateriya S, Musti AM, Bamberg E, Hegemann P (2002) Channelrhodopsin-1: a light-gated proton channel in green algae. Science 296:2395-2398

Nagel G, Szellas T, Huhn W, Kateriya S, Adeishvili N, Berthold P, Ollig D, Hegemann P, Bamberg E (2003) Channelrhodopsin-2, a directly light-gated cation-selective membrane channel. Proc Natl Acad Sci USA 100:13940-13945

Nagel G, Brauner M, Liewald JF, Adeishvili N, Bamberg E, Gottschalk A (2005) Light activation of channelrhodopsin-2 in excitable cells of Caenorhabditis elegans triggers rapid behavioral responses. Curr Biol 15:2279-2284

Nathanson JL, Jappelli R, Scheeff ED, Manning G, Obata K, Brenner S, Callaway EM (2009) Short promoters in viral vectors drive selective expression in mammalian inhibitory neurons, but do not restrict activity to specific inhibitory cell-types. Front Neural Circuits 3:19

Navarro-Quiroga I, Chittajallu R, Gallo V, Haydar TF (2007) Longterm, selective gene expression in developing and adult hippocampal pyramidal neurons using focal in utero electroporation. J Neurosci 27:5007-5011

Oesterhelt D, Stoeckenius W (1971) Rhodopsin-like protein from the purple membrane of Halobacterium halobium. Nat New Biol 233:149-152

Oesterhelt D, Stoeckenius W (1973) Functions of a new photoreceptor membrane. Proc Natl Acad Sci USA 70:2853-2857

Oh E, Maejima T, Liu C, Deneris E, Herlitze S (2010) Substitution of 5-HT1A receptor signaling by a light-activated $\mathrm{G}$ protein-coupled receptor. J Biol Chem 285:30825-30836

Petreanu L, Huber D, Sobczyk A, Svoboda K (2007) Channelrhodopsin-2-assisted circuit mapping of long-range callosal projections. Nat Neurosci 10:663-668

Petreanu L, Mao T, Sternson SM, Svoboda K (2009) The subcellular organization of neocortical excitatory connections. Nature 457: $1142-1145$

Pulver SR, Pashkovski SL, Hornstein NJ, Garrity PA, Griffith LC (2009) Temporal dynamics of neuronal activation by Channelrhodopsin-2 and TRPA1 determine behavioral output in Drosophila larvae. J Neurophysiol 101:3075-3088

Racker E, Stoeckenius W (1974) Reconstitution of purple membrane vesicles catalyzing light-driven proton uptake and adenosine triphosphate formation. J Biol Chem 249:662-663

Royer S, Zemelman BV, Barbic M, Losonczy A, Buzsaki G, Magee JC (2010) Multi-array silicon probes with integrated optical fibers: light-assisted perturbation and recording of local neural circuits in the behaving animal. Eur J Neurosci 31:2279-2291 
Saito T (2006) In vivo electroporation in the embryonic mouse central nervous system. Nat Protoc 1:1552-1558

Schobert B, Lanyi JK (1982) Halorhodopsin is a light-driven chloride pump. J Biol Chem 257:10306-10313

Schoonheim PJ, Arrenberg AB, Del BF, Baier H (2010) Optogenetic localization and genetic perturbation of saccade-generating neurons in zebrafish. J Neurosci 30:7111-7120

Schultheis C, Liewald JF, Bamberg E, Nagel G, Gottschalk A (2011) Optogenetic long-term manipulation of behavior and animal development. PLoS One 6:e18766

Scott EK, Mason L, Arrenberg AB, Ziv L, Gosse NJ, Xiao T, Chi NC, Asakawa K, Kawakami K, Baier H (2007) Targeting neural circuitry in zebrafish using GAL4 enhancer trapping. Nat Methods 4:323-326

Shepherd GM, Svoboda K (2005) Laminar and columnar organization of ascending excitatory projections to layer $2 / 3$ pyramidal neurons in rat barrel cortex. J Neurosci 25:5670-5679

Sohal VS, Zhang F, Yizhar O, Deisseroth K (2009) Parvalbumin neurons and gamma rhythms enhance cortical circuit performance. Nature 459:698-702

Stierl M, Stumpf P, Udwari D, Gueta R, Hagedorn R, Losi A, Gartner W, Petereit L, Efetova M, Schwarzel M, Oertner TG, Nagel G, Hegemann P (2011) Light modulation of cellular cAMP by a small bacterial photoactivated adenylyl cyclase, bPAC, of the soil bacterium Beggiatoa. J Biol Chem 286:1181-1188

Stroh A, Tsai HC, Ping WL, Zhang F, Kressel J, Aravanis A, Santhanam N, Deisseroth K, Konnerth A, Schneider MB (2011) Tracking stem cell differentiation in the setting of automated optogenetic stimulation. Stem Cells 29:78-88

Stuber GD, Sparta DR, Stamatakis AM, van Leeuwen WA, Hardjoprajitno JE, Cho S, Tye KM, Kempadoo KA, Zhang F, Deisseroth K, Bonci A (2011) Excitatory transmission from the amygdala to nucleus accumbens facilitates reward seeking. Nature 475:377-380

Svoboda K, Yasuda R (2006) Principles of two-photon excitation microscopy and its applications to neuroscience. Neuron 50:823-839

Tsai HC, Zhang F, Adamantidis A, Stuber GD, Bonci A, de Lecea L, Deisseroth K (2009) Phasic firing in dopaminergic neurons is sufficient for behavioral conditioning. Science 324:1080-1084

Tsunoda SP, Hegemann P (2009) Glu 87 of channelrhodopsin- 1 causes $\mathrm{pH}$-dependent color tuning and fast photocurrent inactivation. Photochem Photobiol 85:564-569

Tye KM, Prakash R, Kim SY, Fenno LE, Grosenick L, Zarabi H, Thompson KR, Gradinaru V, Ramakrishnan C, Deisseroth K (2011) Amygdala circuitry mediating reversible and bidirectional control of anxiety. Nature 471:358-362

Wang H, Peca J, Matsuzaki M, Matsuzaki K, Noguchi J, Qiu L, Wang D, Zhang F, Boyden E, Deisseroth K, Kasai H, Hall WC, Feng G, Augustine GJ (2007) High-speed mapping of synaptic connectivity using photostimulation in channelrhodopsin-2 transgenic mice. Proc Natl Acad Sci USA 104:8143-8148

Wang H, Sugiyama Y, Hikima T, Sugano E, Tomita H, Takahashi T, Ishizuka T, Yawo H (2009) Molecular determinants differentiat- ing photocurrent properties of two channelrhodopsins from chlamydomonas. J Biol Chem 284:5685-5696

Weick JP, Johnson MA, Skroch SP, Williams JC, Deisseroth K, Zhang SC (2010) Functional control of transplantable human ESC-derived neurons via optogenetic targeting. Stem Cells 28:20082016

Wen L, Wang H, Tanimoto S, Egawa R, Matsuzaka Y, Mushiake H, Ishizuka T, Yawo H (2010) Opto-current-clamp actuation of cortical neurons using a strategically designed channelrhodopsin. PLoS One 5:e12893

Witten IB, Lin SC, Brodsky M, Prakash R, Diester I, Anikeeva P, Gradinaru V, Ramakrishnan C, Deisseroth K (2010) Cholinergic interneurons control local circuit activity and cocaine conditioning. Science 330:1677-1681

Xu ZL, Mizuguchi H, Ishii-Watabe A, Uchida E, Mayumi T, Hayakawa T (2001) Optimization of transcriptional regulatory elements for constructing plasmid vectors. Gene 272:149-156

Yizhar O, Fenno LE, Davidson TJ, Mogri M, Deisseroth K (2011a) Optogenetics in neural systems. Neuron 71:9-34

Yizhar O, Fenno LE, Prigge M, Schneider F, Davidson TJ, O'Shea DJ, Sohal VS, Goshen I, Finkelstein J, Paz JT, Stehfest K, Fudim R, Ramakrishnan C, Huguenard JR, Hegemann P, Deisseroth K (2011b) Neocortical excitation/inhibition balance in information processing and social dysfunction. Nature 477(7363):171-178

Zhang YP, Oertner TG (2007) Optical induction of synaptic plasticity using a light-sensitive channel. Nat Methods 4:139-141

Zhang F, Wang LP, Brauner M, Liewald JF, Kay K, Watzke N, Wood PG, Bamberg E, Nagel G, Gottschalk A, Deisseroth K (2007a) Multimodal fast optical interrogation of neural circuitry. Nature 446:633-639

Zhang F, Aravanis AM, Adamantidis A, de Lecea L, Deisseroth K (2007b) Circuit-breakers: optical technologies for probing neural signals and systems. Nat Rev Neurosci 8:577-581

Zhang W, Ge W, Wang Z (2007c) A toolbox for light control of Drosophila behaviors through channelrhodopsin 2-mediated photoactivation of targeted neurons. Eur J Neurosci 26:2405-2416

Zhang F, Prigge M, Beyriere F, Tsunoda SP, Mattis J, Yizhar O, Hegemann P, Deisseroth K (2008) Red-shifted optogenetic excitation: a tool for fast neural control derived from Volvox carteri. Nat Neurosci 11:631-633

Zhang J, Laiwalla F, Kim JA, Urabe H, Van WR, Song YK, Connors BW, Zhang F, Deisseroth K, Nurmikko AV (2009) Integrated device for optical stimulation and spatiotemporal electrical recording of neural activity in light-sensitized brain tissue. J Neural Eng 6:055007

Zhang F, Gradinaru V, Adamantidis AR, Durand R, Airan RD, de Lecea L, Deisseroth K (2010) Optogenetic interrogation of neural circuits: technology for probing mammalian brain structures. Nat Protoc 5:439-456

Zhao S, Cunha C, Zhang F, Liu Q, Gloss B, Deisseroth K, Augustine GJ, Feng G (2008) Improved expression of halorhodopsin for light-induced silencing of neuronal activity. Brain Cell Biol 36:141-154 